\title{
Utility of Minimum Inhibitory Concentration values and Antibiotyping for Epidemiological study of Vancomycin Resistant Enterococci in a Tertiary Care Hospital
}

\author{
Deepa Devhare \\ Department of Microbiology, Bharati Vidyapeeth Medical College, Pune - 411043, Maharashtra, India.
}

\begin{abstract}
Vancomycin-resistant enterococci (VRE) have emerged as an important nosocomial infection. Three important vancomycin resistance types namely, VanA, VanB, VanC are very commonly found in enterococci. VanA and VanB are plasmid-encoded, transferable types of resistance and VanC is chromosomally mediated nontransferable resistance. So for infection control purposes it is important to know the type of vancomycin resistance to prevent the spread of drug resistance. Enterococci isolated from clinical samples were tested for vancomycin resistance by disc diffusion and macro broth dilution (MIC) method. Vancomycin resistance gene was detected by the polymerase chain reaction (PCR) method. Antimicrobial susceptibility for penicillin, erythromycin, ciprofloxacin, highlevel gentamicin, nitrofurantoin, tetracycline, teicoplanin and linezolid was performed by disc diffusion method. Antibiotyping of VRE strains was done based on their antimicrobial susceptibility pattern. Over a period of one year out of 246 clinical isolates of enterococci, seven $(2.8 \%)$ isolates showed vancomycin resistance. Based on MICs and PCR, all the isolates demonstrated VanA type of resistance. Analysis of antibiogram showed three different antibiotype patterns for VRE labelled as 1,2,3. The majority of VRE isolates (72\%) belonged to "Pattern 1". Also clustering of cases of "Pattern 1" was observed in medicine ICU and medicine ward. These areas were identified as a potential reservoir for VRE infection and appropriate infection control measures were taken to curtail the spread of infection. The present study recommends a macro broth dilution method for detection of the type of vancomycin resistance in enterococci and "antibiotyping" as a basic typing method for VRE in resource-poor health care settings specifically in outbreak situations.
\end{abstract}

Keyword: VRE, VanA, MIC, phenotyping, outbreak

*Correspondence: deepadevhare@gmail.com; +91 9970004523

(Received: August 23, 2021; accepted: September 27, 2021)

Citation: Devhare D. Utility of Minimum Inhibitory Concentration values and Antibiotyping for Epidemiological study of Vancomycin Resistant Enterococci in a Tertiary Care Hospital. J Pure Appl Microbiol. 2021;15(4):1995-2002. doi: 10.22207/ JPAM.15.4.21

(C) The Author(s) 2021. Open Access. This article is distributed under the terms of the Creative Commons Attribution 4.0 International License which permits unrestricted use, sharing, distribution, and reproduction in any medium, provided you give appropriate credit to the original author(s) and the source, provide a link to the Creative Commons license, and indicate if changes were made. 


\section{INTRODUCTION}

Enterococci are part of normal microbial flora of oral cavity, gut and genitourinary tract. ${ }^{1}$ They are ubiquitously found in different environments such soil, water, sewage and plants. ${ }^{2}$ Being opportunistic pathogens enterococci cause infections in susceptible host. Enterococci specifically $E$. faecium has inherent tendency to acquire resistance against multiple group of antibiotics, which makes enterococci an important cause of nosocomial infections. ${ }^{3}$

Vancomycin is the high end antibiotic which can be used for treatment of infections caused by multidrug resistant enterococci. ${ }^{4,5}$ Enterococci have developed resistance against vancomycin also known as Vancomycin resistant enterococci (VRE). Emergence of VRE is largely related to inappropriate use of antibiotics mainly vancomycin in health care settings. ${ }^{6}$ Different infections caused by VRE includes endocarditis, septicemia, urinary tract infections, wound infections, intraabdominal infections mainly in hospitalized patients. ${ }^{7}$

There are three important vancomycin resistance types described in literature (VanA, VanB, VanC). VanA and VanB are types of acquired vancomycin resistance. Van $A$ and VanB are plasmid encoded and can spread from organism to organism causing major outbreaks in hospitals. VanA type shows high level resistance to vancomycin (MIC of $\geq 128 \mu \mathrm{g} / \mathrm{ml}$ ) and teicoplanin (MIC of $\geq 16 \mu \mathrm{g} / \mathrm{ml}$ ). VanB phenotypes are resistant to low levels of vancomycin (MIC of 16 to $64 \mu \mathrm{g}$ / $\mathrm{ml}$ ) but sensitive to teicoplanin (MIC of $\leq 1 \mu \mathrm{g}$ / $\mathrm{ml}$ ). VanC gene, is chromosomally encoded and cannot be transferred from one organism to other. Therefore it has not been associated with hospital acquired infections. VanC is an intrinsic type of drug resistance present in E.gallinarum and E.casseli flavus and produce vancomycin MIC of 2 to $16 \mu \mathrm{g} / \mathrm{ml}$. Hence it is important to perform species level identification of Enterococci, as it has different implications in hospital infection control measures. Based on the MIC values of vancomycin and teicoplanin, enterococci can be classified as VanA, VanB and VanC phenotypes. ${ }^{8}$

Knowing the species of Enterococci and type of vancomycin resistance, we can implement appropriate infection control measures to prevent spread of resistance in healthcare settings.
Antimicrobial susceptibility pattern of organism can also guide in identifying different antibiotypes of VRE to study their epidemiology in an outbreak situation. ${ }^{9}$ If there is a single or one major antibiotype which is being repeatedly isolated from different patients in same hospital setting then one can suspect circulation of same strain in hospital set up giving rise to nosocomial infections. The source or reservoir of nosocomial outbreak can be detected by locating the area in the hospital like any specific ward or ICU from where there is repeated isolation of the same species with similar antibiotype. After identifying such areas in the hospital, strict infection control measures can be implemented to curtail the outbreak. ${ }^{6,10}$ Author has described molecular method for genotyping of VRE strains isolated in health care set up ${ }^{11}$ but phenotypic methods for typing of VRE strains for epidemiological study are not well described in literature. ${ }^{12}$ Based on this background present study was conducted to

1. To isolate and identify the VRE strains from clinical samples

2. To study the antibiotic susceptibility pattern of VRE strains

3. Antibiotyping of VRE isolates based on the antibiotic susceptibility pattern

4. To detect the MIC values of vancomycin and teicoplanin in VRE strains to determine type of vancomycin drug resistance

5. Confirmation of type of vancomycin resistance in enterococci by Polymerase chain reaction

\section{MATERIAL AND METHODS}

A prospective cross sectional study was conducted over a period of one year from January 2013- December 2013 in a tertiary care hospital in Pune, Maharashtra, India. Institutional Ethical Committee approval was taken for the study. (Reference number- BMC/IEC/Pharmac/ D0313005-05). Informed consent and detail clinical history was taken from all patients.

\section{Study population}

Patients of all age groups and both sexes attending the inpatient and outpatient departments of a tertiary care hospital in western Maharashtra, India.

\section{Sample size}

Total 246 enterococci strains isolated from clinical samples like urine, blood, CSF, 
pleural fluid, ascetic fluid, pus, wound swabs of the patients, attending the hospital with different types of infections were included in the study.

\section{Isolation and identification of Enterococcus} species from clinical samples

Blood agar and MacConkey agar plates were used for inoculation of clinical samples and incubated under aerobic conditions at $37^{\circ} \mathrm{C}$ for 24-48 hrs. Colony morphology, catalase test and Gram stain were used for preliminary identification of Enterococci. For genus level identification of Enterococcus species, Bile esculin hydrolysis test, $6.5 \%$ salt tolerance test, Pyrrolidonyl arylamisase (PYR) tests were used. Species level identification was done only for isolates showing resistance to vancomycin by Kirby Bauer disc diffusion method. For speciation mannitol fermentation, motility, pigment production, Arabinose fermentation and Arginine hydrolysis tests were used., ${ }^{7,13-14}$

\section{Antimicrobial susceptibility testing}

Kirby- Bauer disc diffusion method was used to perform antimicrobial susceptibility of Enterococci isolated from clinical samples as per CLSI guidelines. Antibiotics used for testing were penicillin (10 units), erythomycin $(15 \mu \mathrm{g})$, tetracycline $(30 \mu \mathrm{g})$, cipofloxacin $(5 \mu \mathrm{g})$, high level gentamicin $(120 \mu \mathrm{g})$, nitofurantoin $(300 \mu \mathrm{g})$, vancomycin $(30 \mu \mathrm{g})$, teicoplanin $(30 \mu \mathrm{g})$ and linezolid $(30 \mu \mathrm{g})$. Antibiotic discs were procured from $\mathrm{Hi}$-media laboratories private limited, India. ${ }^{15}$

For vancomycin disc, zone size of $\geq 17$ $\mathrm{mm}$ was considered sensitive, $15-16 \mathrm{~mm}$ was
Table 1. Showing classification of vancomycin drug resistance based on MIC values

\begin{tabular}{lcc}
\hline $\begin{array}{l}\text { Type of vancomycin } \\
\text { resistance }\end{array}$ & $\begin{array}{l}\text { Vancomycin } \\
\mathrm{MIC}(\mu \mathrm{g} / \mathrm{ml})\end{array}$ & $\begin{array}{c}\text { Teicoplanin } \\
\mathrm{MIC}(\mu \mathrm{g} / \mathrm{ml})\end{array}$ \\
\hline Van $A$ & $\geq 128$ & $\geq 16$ \\
$\operatorname{Van} B$ & $16-64$ & $\leq 1$ \\
$\operatorname{Van} C$ & $2-16$ & $\leq 1$ \\
\hline
\end{tabular}

considered intermediate resistant and $\leq 14 \mathrm{~mm}$ was considered resistant. ${ }^{15}$ Enterococci showing vancomycin drug resistance by disc diffusion were presumptively considered as VRE strains. Organism resistant to more than 3 groups of antibiotics were considered multidrug resistant. ${ }^{16}$

\section{Antibiotyping of VRE isolates}

Antimicrobial susceptibility patterns of VRE strains were analyzed. Organisms with same antibiogram were grouped together. All such groups with different antibiogram were identified and labeled as "antibiotype patterns." ${ }^{17}$

VRE strains identified by disc diffusion method were further tested by Macro broth dilution method to determine MIC values for vancomycin and teicoplanin. Serial dilutions of vancomycin and teicoplanin ( Hi-media private limited, India) were prepared in cation adjusted Muller Hinton broth (CAMHB) broth. Liquid culture of the test organism was matched with $0.5 \mathrm{McF}$ arland's turbidity standard. $10 \mu \mathrm{L}$ bacterial culture was inoculated in broth with different concentrations of vancomycin. Broths were

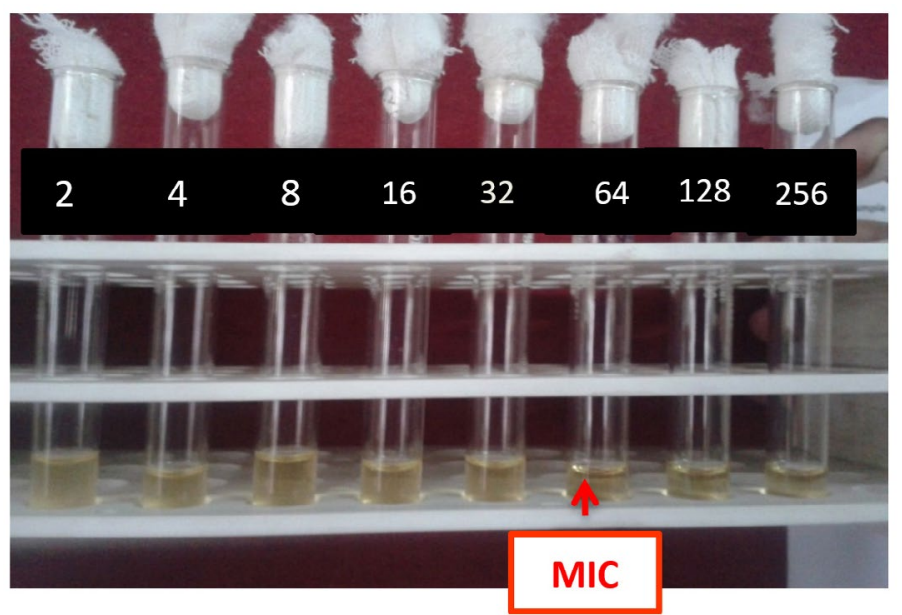

Fig. 1. Macrobroth dilution method for detection of MIC. 
incubated at $37^{\circ} \mathrm{C}$ for $24 \mathrm{hrs}$. Minimum inhibitory concentration was determined based on the concentration of vancomycin and teicoplanin which inhibited visible growth of test organism in broth. (Fig. 1) Vancomycin MIC of $\geq 32 \mu \mathrm{g} / \mathrm{mL}$ was considered resistant; MIC of $8-16 \mu \mathrm{g} / \mathrm{mL}$ as intermediate resistant; and MIC of $\leq 4 \mu \mathrm{g} / \mathrm{mL}$ was considered as sensitive. Teicoplanin MIC of $\geq 32 \mu \mathrm{g} /$ $\mathrm{mL}$ was considered resistant; MIC of $16 \mu \mathrm{g} / \mathrm{mL}$ as intermediate resistant; and MIC of $\leq 8 \mu \mathrm{g} / \mathrm{mL}$ was considered as sensitive. ${ }^{15,18,19}$ ATCC E. fecalis 29212 was used as quality control strain for disc diffusion and macro broth dilution method.

MIC values of vancomycin and teicoplanin were analyzed to determine the type of vancomycin drug resistance as shown in Table $1 .{ }^{8}$

Polymerase chain reaction (PCR)

DNA extraction of enterococci with vancomycin drug resistance confirmed by macrobroth dilution method was done by silica gel method. PCR for van A gene was performed first, with van A forward-GTAGGCTGCGATATTCAAAGC and van $A$ reverse- CGATTCAATTGCGTAGTCCAA primers. PCR master mix (Bangalore Genie), VRE DNA and primers were subjected to PCR cycles $\left(94^{\circ} \mathrm{C} / 2 \mathrm{~min}, 60^{\circ} \mathrm{C} / 2 \mathrm{~min}\right.$, final extension $72^{\circ} \mathrm{C} / 2 \mathrm{~min}$ ). Electrophoresis with $2 \%$ agarose gel was used for analyzing the PCR amplified product under UV light. (Fig. 2) VRE isolates negative for vanA PCR were subjected to $P C R$ for vanB gene. Primers for van B were forward
Table 2. Antibiotic susceptibility pattern of VRE

\begin{tabular}{lc}
\hline Antibiotic & VRE strains $(\mathrm{n}=7)(\%)$ \\
\hline Penicillin (10units) & 0 \\
Erythromycin $(15 \mu \mathrm{g})$ & 0 \\
Ciprofloxacin $(5 \mu \mathrm{g})$ & 0 \\
Tetracycline $(30 \mu \mathrm{g})$ & $1(14.3 \%)$ \\
Nitrofurantoin $(300 \mathrm{ug})$ & $2(28.6 \%)$ \\
Teicoplanin $(30 \mu \mathrm{g})$ & 0 \\
Linezolid $(30 \mu \mathrm{g})$ & $7(100 \%)$ \\
Vancomycin $(30 \mu \mathrm{g})$ & 0 \\
High level Gentamicin & 0 \\
(HLG) $(120 \mathrm{~g})$ & \\
\hline
\end{tabular}

GTAGGCTGCGATATTCAAAGC van B revers GCCGACAATCAAATCATCCTC. ${ }^{11,20-22}$

\section{RESULTS}

In present study, total 246 Enterococci strains were isolated from clinical samples. Out of these 246 strains of Enterococcus species, seven (2.8\%) isolates showed vancomycin drug resistance by disc diffusion method. Sensitivity of these seven vancomycin resistant enterococci to other tested antibiotics is shown in Table 2. All the isolates of VRE were multidrug resistant. Other than glycopeptides, $100 \%$ resistance was observed to penicillin, erythromycin, ciprofloxacin, HLG in VRE strains. VRE showed maximum sensitivity to linezoild (100\%). All seven strains of VRE were found to be E. faecium by species level



Fig. 2. Gel electrophoresis of amplified products by PCR for vancomycin resistance genes. 
identification. These seven VRE isolates were numbered "VRE I-VII" for further analysis.

Based on antibiotic susceptibility pattern of these seven VRE isolates, three different susceptibility patterns were identified which were labeled as antibiotype pattern 1, 2 and 3. Pattern 1 was the most common pattern having 5 out of 7 VRE strains (72\%) showed resistance to 8 antibiotics out of 9 tested antibiotics. Pattern 2 had single VRE isolate with resistance to 6 antibiotics and Pattern 3 with single VRE strain showing resistance to 7 antibiotics. (Table 3).

All seven strains of Enterococci showing vancomycin drug resistance by disc diffusion method had high MIC values for vancomycin and teicoplanin by macro broth dilution method. Based on the MIC values of vancomycin and teicoplanin, all the VRE strains demonstrated van A type of

Table 3. Antibiotyping of VRE isolates based on antimicrobial susceptibility patterns

\begin{tabular}{|c|c|c|c|}
\hline Antibiotic & $\begin{array}{l}\text { Pattern1 } \\
(n=5)\end{array}$ & $\begin{array}{l}\text { Pattern2 } \\
(\mathrm{n}=1)\end{array}$ & $\begin{array}{l}\text { Pattern3 } \\
(n=1)\end{array}$ \\
\hline Penicillin (10units) & $\mathrm{R}$ & $\mathrm{R}$ & $\mathrm{R}$ \\
\hline Erythromycin $(15 \mu \mathrm{g})$ & $\mathrm{R}$ & $\mathrm{R}$ & $\mathrm{R}$ \\
\hline Ciprofloxacin $(5 \mu \mathrm{g})$ & $\mathrm{R}$ & $\mathrm{R}$ & $\mathrm{R}$ \\
\hline Tetracycline $(30 \mu \mathrm{g})$ & $\mathrm{R}$ & $S$ & $\mathrm{R}$ \\
\hline Nitrofurantoin (300ug) & $\mathrm{R}$ & $S$ & $S$ \\
\hline Vancomycin $(30 \mu \mathrm{g})$ & $\mathrm{R}$ & $\mathrm{R}$ & $\mathrm{R}$ \\
\hline Teicoplanin $(30 \mu \mathrm{g})$ & $\mathrm{R}$ & $\mathrm{R}$ & $\mathrm{R}$ \\
\hline Linezolid $(30 \mu \mathrm{g})$ & $S$ & $S$ & $S$ \\
\hline $\begin{array}{l}\text { High level Gentamicin } \\
\text { (HLG) (120g) }\end{array}$ & $\mathrm{R}$ & $\mathrm{R}$ & $\mathrm{R}$ \\
\hline
\end{tabular}

vancomycin resistance. PCR detected vanA gene in all 7 isolates of VRE in present study. (Table 4) Out of 5 isolates with antibiotype Pattern I, 4 isolates had same MIC values for vancomycin $(128 \mathrm{ug} / \mathrm{ml})$ and 3 isolates had same MIC value for teicoplanin. Patient's location in the hospital was traced. All the patients were indoor patients, admitted in hospital. Ward wise distribution of VRE isolates showed clustering of the cases in medicine ICU (MICU) followed by Ward 19 with same antibiotype Pattern 1 and van A type of resistance. (Fig. 3)

\section{DISCUSSION}

Enterococci can survive for a longer period in hospital environment and create hurdles for infection control in hospitals. ${ }^{23}$ Identifying VRE cases and type of vancomycin resistance is very important to prevent spread of resistance from patient to patient in a health care set up. ${ }^{24}$

In present study, prevalence of VRE was found to be $2.8 \%$. Studies conducted by Mathur et al. and Taneja et al. are in comparison with present study, which showed $1 \%$ and $5.5 \%$ prevalence of VRE in their studies respectively. ${ }^{25,26}$ Prevalence of VRE was high in studies conducted by Karmarkar et al., Oberoi et al. and Deshpande et al. Difference in prevalence of VRE can be attributed to different study population and extent of vancomycin usage in different hospital settings. ${ }^{27-29}$

Enterococci are intrinsically resistant to multiple routinely used antibiotics and they can also acquire resistance by transfer of genetic material through conjugation..$^{13}$ In present study,

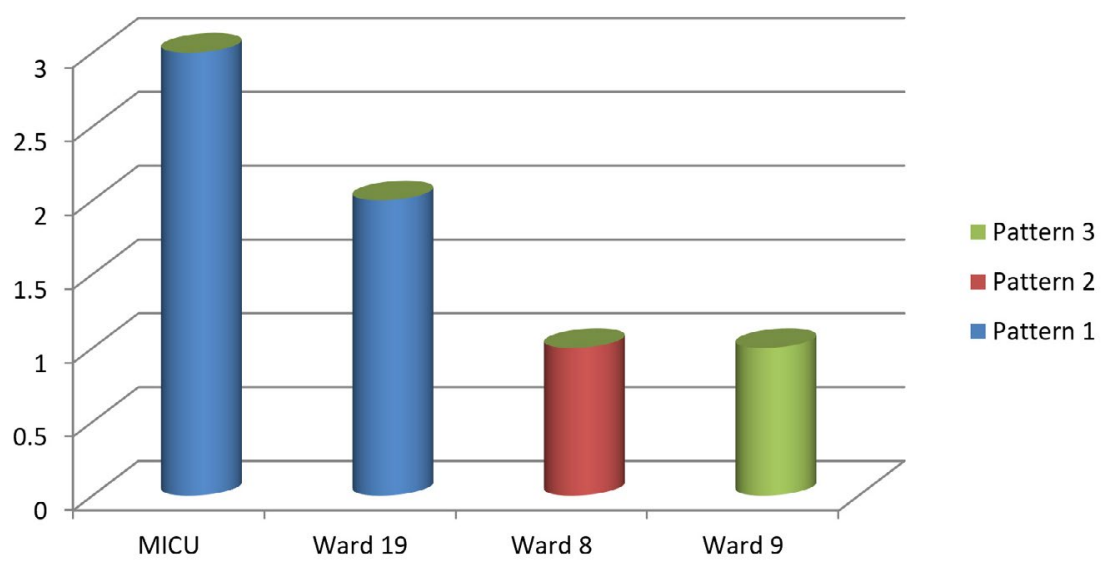

Fig. 3. Ward wise distribution of VRE antibiotype patterns 
Table 4. Detection of type of vancomycin drug resistance based on MIC and PCR

\begin{tabular}{llccccc}
\hline $\begin{array}{l}\text { VRE } \\
\text { Isolate } \\
\text { No. }\end{array}$ & Species & $\begin{array}{c}\text { Vancomycin } \\
\text { MIC value } \\
(\mu \mathrm{g} / \mathrm{ml})\end{array}$ & $\begin{array}{c}\text { Teicoplanin } \\
\text { MIC value } \\
(\mu \mathrm{g} / \mathrm{ml})\end{array}$ & $\begin{array}{c}\text { Vancomycin } \\
\text { resistance type } \\
\text { based on MIC }\end{array}$ & $\begin{array}{c}\text { Gene } \\
\text { By PCR }\end{array}$ & $\begin{array}{c}\text { Antibio- } \\
\text { type } \\
\text { Pattern }\end{array}$ \\
\hline I & E.faecium & 128 & 256 & Van A & vanA & 1 \\
II & E.faecium & 256 & 16 & Van A & vanA & 2 \\
III & E.faecium & 256 & 256 & Van A & vanA & 1 \\
IV & E.faecium & 256 & 256 & Van A & vanA & 3 \\
V & E.faecium & 128 & 64 & Van A & vanA & 1 \\
VI & E.faecium & 128 & 256 & Van A & vanA & 1 \\
VII & E.faecium & 128 & 256 & Van A & vanA & 1 \\
\hline
\end{tabular}

all 7 isolates of VRE were found to be multidrug resistant and belonged to species E.faecium. VRE strains showed maximum sensitivity to linezolid (100\%) followed by nitrofurantoin $(28.6 \%)$ and tetracycline (14.3\%). Other Indian studies have also demonstrated multidrug resistant pattern in VRE isolates. ${ }^{24,30,31}$ E. faecium showed more resistance as compared to $\mathrm{E}$. faecalis for all tested antibiotics in studies conducted Deshpande et al., by Rahangdale et al., and Baragundi et al. ${ }^{29,31,32}$

Typing of organisms causing nosocomial infections is essential and useful for studying the epidemiology of infections. It helps in implementing infection control measures in a health care set up. . "Antibiotyping" of VRE strains was used as a phenotypic typing method in present study, which revealed presence of three different susceptibility patterns of VRE. "Pattern 1" $(72 \%)$ was the commonest having most resistant strains sensitive only to linezolid (100\%).

By macro broth dilution method and $P C R$, all seven isolates of VRE showed vanA type of vancomycin resistance. Present study demonstrates $100 \%$ correlation between phenotypic (MIC) and genotypic (PCR) methods for detection of type of vancomycin resistance in Enterococci. Our findings are in agreement with previous studies conducted by Modi et al., Bekhit



Antibiogram and MIC values were very informative in present study to understand the epidemiology of VRE. Five out of seven VRE isolates showed antibiotype pattern 1 with van $A$ type of drug resistance. Maximum isolates (4/5) from antibiotype pattern 1 showed same MIC value $(128 \mathrm{ug} / \mathrm{ml})$ for vancomycin. These findings suggested existence of high level transferable vancomycin resistance in the hospital setting, which was serious concern from infection control point of view. These findings further triggered the need for detection of any common source or reservoir for infection.

Analysis of antibiotype patterns, MIC values and type of drug resistance, in relation to patient location in hospital, highlighted clustering of same VRE clone in MICU (43\%) followed by ward 19 (29\%). Ward 19 was also located on the same floor as that of MICU and belonged to Medicine department. Transfer of patients between these two wards (MICU and ward 19) was routine activity. These areas were suspected as potential reservoirs for VRE, causing patient to patient spread of VRE. ${ }^{35}$ Role of environment and contaminated medical devices in the VRE transmission in outbreaks is well documented in literature. ${ }^{6}$ Heath care workers who are carriers of enterococci are less often involved in transmission of VRE. ${ }^{36}$ Rigorous infection control measures like thorough environmental cleaning, hand hygiene, isolation and barrier nursing of VRE infected patients, use of personal protective equipments, contact precautions were implemented in the affected wards. ${ }^{6}$ This study resulted in more awareness in the hospital staff about nosocomial infections and appropriate infection control measures were implemented to prevent further spread of VRE in hospital set up.

\section{CONCLUSION}

Detection of type of resistance is important for implementation of infection control measures in a health care set up. Present study recommends use of broth dilution as a simple and cost effective method as compared to genotypic 
methods for detection of type of vancomycin resistance (VanA, VanB, VanC). Although newer advanced methods have been discovered for typing of bacteria," antibiotyping" still stands as the most simple and rapid typing method for bacterial isolates in resource poor hospital settings particularly in outbreak situations.

\section{ACKNOWLEDGMENTS}

None.

\section{FUNDING}

None.

\section{DATA AVAILABILITY}

All datasets generated or analyzed during this study are included in the manuscript.

\section{ETHICS STATEMENT}

The study was approved by the institutional ethics committee of B.J. Govt. Medical College, Pune with protocol reference numberBMC/IEC/Pharmac/D0313005-05.

\section{REFERENCES}

1. Archibald L, Phillips L, Monnet D, McGowan JE Jr, Tenover F, Gaynes R. Antimicrobial resistance in isolates from inpatients and outpatients in the United States : increasing importance of the intensive care unit. Clin Infect Dis. 1997;24(2):211-215. doi: 10.1093/ clinids/24.2.211

2. Braiek O, Smaoui S. Enterococci: Between Emerging Pathogens and Potential Probiotics. BioMed Research International. 2019;2019:5938210. doi: 10.1155/2019/5938210

3. Eliopoulos GM, Gold HS. Vancomycin-Resistant Enterococci : Mechanisms and Clinical Observations. Clin Infect Dis. 2001;33(2):210-219. doi: $10.1086 / 321815$

4. Melese A, Genet C, Andualem T. Prevalence of Vancomycin resistant enterococci (VRE) in Ethiopia: a systematic review and meta-analysis. BMC Infect Dis. 2020;20(1):124. doi: 10.1186/s12879-020-4833-2

5. Jensen BJ. Screening Specimens for VancomycinResistant Enterococcus. Laboratory Medicine. 1996;27(1):53-55. doi: 10.1093/labmed/27.1.53

6. Hospital Infection Control Practices Advisory Committee (HICPAC). Recommendations for preventing the spread of vancomycin resistance. Infect Control Hosp Epidemiol. 1995;16(2):105-113. doi: 10.1086/647066

7. Cetinkaya Y, Falk P, Mayhall CG. Vancomycin-resistant Enterococci. Clin Microbiol Rev. 2000;13(4):686-707. doi: 10.1128/CMR.13.4.686

8. Teo JWP, Krishnan P, Jureen R, Lin RTP. Detection of an Unusual van Genotype in a Vancomycin-Resistant
Enterococcus faecium Hospital Isolate. J Clin Microbiol. 2011;49(12):4297-4298. doi: 10.1128/JCM.05524-11

9. Biswal I, Arora B, Kasana D, Neetushree. Incidence of Multidrug Resistant Pseudomonas Aeruginosa Isolated from Burn Patients and Environment of Teaching Institution. J Clin Diagn Res. 2014;8(5):DC26-DC29. doi: $10.7860 / J C D R / 2014 / 7483.4383$

10. Ducel G, Fabry J, Nicolle L. World Health Organization. Prevention of hospital-acquired infections A practical guide $2^{\text {nd }}$ Edition 2002. WHO/CDS/CSR/EPH/2002.12

11. Pol S, Devhare D, Bharadwaj R. Vancomycin resistant enterococci: an emerging problem in a tertiary care hospital, Pune. India International Journal of Medical Microbiology and Tropical Diseases. 2017;3(1):27-30.

12. Farman M, Yasir M, Al-Hindi R, et al. Genomic analysis of multidrug-resistant clinical Enterococcus faecalis isolates for antimicrobial resistance genes and virulence factors from the western region of Saudi Arabia. Antimicrob Resist Infect Control. 2019;8:55. doi: 10.1186/s13756-019-0508-4

13. Koneman EW, Allen SD, Janda WM, Schreckenberger PC, Winn WC, editors. Gram-positive cocci Part 2: Streptococci, Enterococci and the Streptococcus like bacteria. In: Colour Atlas and Text Book of Diagnostic Microbiology. $6^{\text {th }}$ ed. Philadelphia: Lippincott; 2006:725-33.

14. Betty AF, Daniel LS, Weissfeld AS, editors. Overview of bacterial identifications methods and strategies. In: Bailey \& Scott's Diagnostic Microbiology. 12th ed. Missouri: Mosby Elsevier; 2007:216-241.

15. Clinical and Laboratory Standards Institute(CLSI). Performance Standards for Antimicrobial Susceptibility Testing. M100-23. 2013;33(1). URL= https://www.researchgate.net/file.PostFileLoader. html ? id = 55d77c2f614325f5d38b461b \& assetKey=AS:273836702928896@1442299165694

16. Magiorakos AP. Multidrug Resistant (MDR), Extensively Drug Resistant (XDR) and Pandrug-1 Resistant (PDR) bacteria in healthcare settings. Expert Proposal for a Standardized International Terminology. 2011. www. escmid.org

17. Biendo M, Laurans G, Lefebvre JF, Daoudi F, Eb F. Epidemiological Study of an Acinetobacter baumannii Outbreak by Using a Combination of Antibiotyping and Ribotyping. J Clin Microbiol. 1999;37(7):2170-2175. doi: 10.1128/JCM.37.7.2170-2175.1999

18. Clinical and Laboratory Standard Institute.Methods for Dilution Antimicrobial Susceptibility Tests for Bacteria That Grow Aerobically ; Approved Standard - Ninth Edition. M07-A9. 2012;32(2)." URL= https://www.researchgate.net/file.PostFileLoader. html?id=564ceedf5e9d97daf08b45a2\&asset Key=AS \%3A297254750572544\%401447882463055

19. Murray PR, Baron EJ, Jorgensen JH, Landry ML, Pfaller MA, editors. Special Phenotypic Methods for Detecting Antibacterial Resistance. In: Manual of Clinical Microbiology. $9^{\text {th }}$ ed. Washington, DC: ASM Press; 2007:1152-1172.

20. Boom R, Sol CJ, Salimans MM, Jansen CL, Dillen PMW, van der Noordaa J. Rapid and simple methods for purification of nucleic acids. J Clin Microbiol. 1990;28(3):495-503. doi: 10.1128/jcm.28.3.495- 


\subsection{0}

21. Carter MJ, Milton I. An inexpensive and simple method for DNA purifications on silica particles. Nucleic acid Res. 1993;21(4):1044. doi: 10.1093/nar/21.4.1044

22. Bell JM, Paton JC, Turnidge J. Emergence of vancomycin resistant enterococci in Australia: Phenotypic and genotypic characteristics of isolates. J Clin Microbiol. 1998;36(8):2187-2190. doi: 10.1128/JCM.36.8.21872190.1998

23. Iakas PD, Thapa R, Rice LB, Mylonakis E. Trends and Significance of VRE Colonization in the ICU: A Meta-Analysis of Published Studies. PLoS One. 2013;8(9):e75658. doi: 10.1371/journal.pone.0075658

24. Modi GB, Soni ST, Patel KJ, Goswami HM, Vegad MM. Prevalenace of vancomycin resistant enterococci in tertiary care hospital. Int J Microbiol Res. 2012;4(2):182185. doi: 10.9735/0975-5276.4.2.182-185

25. Mathur P, Kapil A, Chandra R, Sharma P DB. Antimicrobial resistance in Enterococcus faecalis at a tertiary care centre of northern India. Indian J Med Res. 2003;118:25-28.

26. Taneja N, Rani P, Emmanuel R, Sharma M. Significance of vancomycin resistant enterococci from urinary specimens at a tertiary care centre in Northern India. Indian J Med Res. 2004;119(2):72-74.

27. Karmarkar M, Gershom E, Mehta P. Enterococcal infections with special reference to phenotypic characterization \& drug resistance. Indian J Med Res. 2014;119:22-25.

28. Oberoi L, Aggarwal A. Multidrug Resistant Enterococci in a Rural Tertiary Care Hospital- A Cause of Concern. JK Sci. 2010;12(3):157-158.

29. Deshpande VR, Karmarkar MG, Mehta PR. Letter to the
Editor Prevalence of multidrug-resistant enterococci in a tertiary care hospital in Mumbai, India. J Infect Dev Ctries. 2013;7(2):155-158. doi: 10.3855/jidc.3018

30. Praharaj I, Sujatha S, Chandra PS. Phenotypic and genotypic characterization of vancomycin resistant Enterococcus isolates from clinical specimens. Ind J Med Res. 2013;138(4):549-556.

31. Rahangdale VA, Agrawal G, Jalgaonkar SV. Study of antimicrobial resistance in enterococci. Indian $\mathrm{J}$ Med Microbiol. 2008;26(3):285-287. doi: 10.4103/02550857.42072

32. Baragundi MC, Sonth SB, Solabannavar S, Patil C, Yemul VL. Species Prevalence And Antimicrobial Resistance Pattern Of Enterococcal Isolates In A Tertiary Health Care Centre. J Clin Diagnostic Res. 2010;4:3405-3409.

33. Bekhit M, Muharram M, Hefni H, Moussa I, Alanazy F. Prevalence and antimicrobial resistance pattern of multidrug-resistant enterococci isolated from clinical specimens. Indian J Med Microbiol. 2012;30(1):44-51. doi: 10.4103/0255-0857.93032

34. Xu X, Lin D, Yan G, et al. VanM, a new glycopeptide resistance gene cluster found in Enterococcus faecium. Antimicrob Agents Chemother. 2010;54:4643-4647. doi: 10.1128/AAC.01710-09

35. Handwerger S, Raucher B, Altarac D, et al. Nosocomial outbreak due to Enterococcus faecium highly resistant to vancomycin, penicillin, and gentamicin. Clin Infect Dis. 1993;16(6):750-755. doi: 10.1093/clind/16.6.750 36. Boyce JM, Opal SM, Chow JW, et al. Outbreak of multidrug resistant Enterococcus faecium with transferable vanB class vancomycin resistance. J Clin Microbiol. 1994;32:1148-1153. doi: $10.1128 / \mathrm{jcm} .32 .5 .1148-$ 1153.1994 